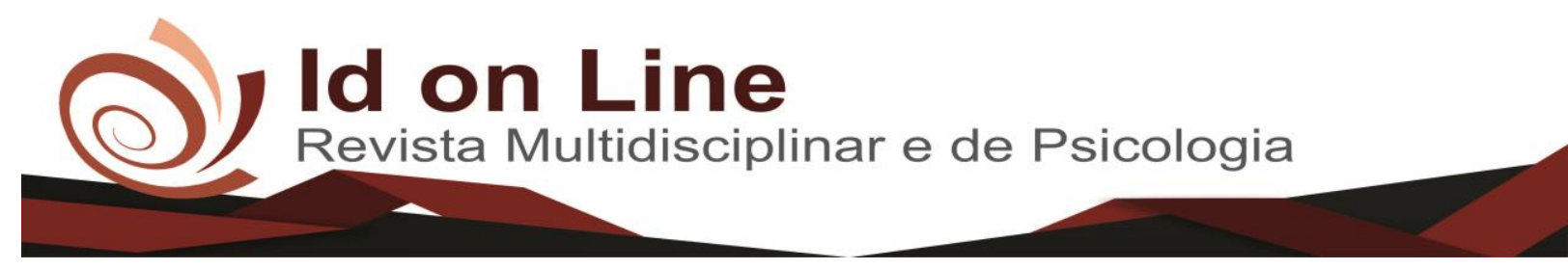

Artigo de Revisão

\title{
Gestão Escolar: Assessoria Pedagógica para o Atendimento de Crianças Down
}

\author{
Denise Rodrigues Dantas ${ }^{1}$; Juan PabloWeschollek Acosta ${ }^{2}$
}

\begin{abstract}
Resumo: O tema do presente estudo é assessoria pedagógica para o atendimento de crianças com Síndrome de Down e seu objetivo é determinar as formas de intervenção da gestão escolar para tornar efetiva a inclusão de crianças Down em classes regulares de ensino, sua aprendizagem e desenvolvimento. O tema é abordado com base na realização de pesquisa bibliográfica qualitativa, concluindo que, a gestão escolar, na realidade dos currículos, dos conteúdos e das práticas pedagógicas da educação inclusiva, apesar do processo inclusivo estar ainda em vias de implantação e aperfeiçoamento, pode e deve lançar um novo olhar sobre as possibilidades da educação inclusiva e, especialmente, sobre as crianças Down que ingressam na escola.
\end{abstract}

Palavras-chave: Gestão escolar; inclusão; Síndrome de Down; assessoria pedagógica.

\section{School Management: Pedagogical Advice for the Care of Children With Down Syndrome}

\begin{abstract}
The purpose of this study is to provide pedagogical advice for the care of children with Down Syndrome and its purpose is to determine the forms of intervention of school management to make the inclusion of Down children in regular classes of their learning and development effective. The theme is approached based on qualitative bibliographical research, concluding that school management, in reality curricula, contents and pedagogical practices of inclusive education, although the inclusive process is still in the process of implementation and improvement, can and should launch a new look at the possibilities of inclusive education, and especially about Down children entering school.
\end{abstract}

Keywords: School management; inclusion; Down's syndrome; pedagogical advice.

\section{Introdução}

A inclusão de alunos com síndrome de Down representa a oportunidade de inclusão social, cujo início se dá no seio familiar e se estende à escola e à vida adulta, proporcionandolhes habilidades, conhecimentos e desenvolvimento do potencial que possuem, proporcionando-lhes ferramentas para a participação cidadã na sociedade.

\footnotetext{
${ }^{1}$ DANTAS, Denise Rodrigues. Graduada em Pedagogia pela Faculdade de Educação da Bahia. FEBA. Atua como Coordenadora Pedagógica desde 1994. Especialista em Coordenação Pedagógica e Psicopedagogia.

${ }^{2}$ ACOSTA, Juan Pablo Weschollek professor orientador. Mestre em Educação pela USACH (Faculdade do Chile). 
Desse processo inclusivo participam a família, o entorno comunitário imediato e todos os seus espaços de convívio e de lazer e, especialmente, a comunidade escolar. Este é o conjunto de escalas a ser conquistado na longa travessia para a plena inclusão social, que se consolida no mundo do trabalho e na vida em sociedade na idade adulta.

Essa travessia é dificultada se, na etapa escolar, momento em que todos os alunos exercem o direito de preparar-se para superarem os desafios da vida social adulta, os alunos com síndrome de Down encontram obstáculos para compartilharem com os demais o direito a uma educação regular.

A escola, portanto, é essencial no caminho para a inclusão plena das pessoas com síndrome de Down e a inclusão em classes regulares de ensino é o modo mais adequado para a escolarização dessas pessoas, embora a mera presença física nas escolas não seja garantia de inclusão verdadeira.

Para consolidar a inclusão, portanto, é necessária a adoção de métodos e de uma organização que proporcione aos alunos com síndrome de Down o suporte que necessitam para aprender e desenvolver-se, que se realizem adaptações nos currículos para incluir realmente, que os professores estejam preparados para educá-los e a escola esteja apta a permitir que se desenvolvam. Desta forma, a inclusão deixa de ser mera declaração de intenções refletida em diversos documentos e passa a ser uma verdade vivida no interior das escolas e na vida dos alunos com síndrome de Down.

Com base nesses pressupostos, o tema do presente estudo é assessoria pedagógica para o atendimento de crianças com Síndrome de Down. O conhecimento que se busca sobre o tema é abordado por diversos pesquisadores e cientistas de diversas áreas, como médicos, sociólogos, psicólogos, educadores, dentre outros. Em relação à assessoria pedagógica para a inclusão de crianças Down, ainda, embora o tema venha sendo vastamente estudado, há espaço para sua ampliação, na medida em que a educação inclusiva avança.

O questionamento que se faz em relação ao tema é: "Quais são os pressupostos necessários para que a escola promova a inclusão do aluno com síndrome de Down no ensino regular de forma eficiente?".

A justificativa para a escolha do tema é a relevância da realização de um estudo que considere diversas abordagens sobre a síndrome, bem como a exigência de que a educação inclusiva seja mais do que uma determinação legislativa, mas uma efetiva etapa da inclusão social cumprida pela escola, capacitada para garantir essa inclusão. 
O objetivo geral do estudo é determinar as formas de intervenção da gestão escolar para tornar efetiva a inclusão de crianças Down em classes regulares de ensino, sua aprendizagem e desenvolvimento. Especificamente, o estudo tem como objetivos definir os desafios existentes para a efetividade de uma educação verdadeiramente inclusiva para esses alunos e determinar ações pedagógicas que favoreçam a inclusão de criança com Síndrome de Down no Ensino Fundamental I.

O estudo segue a metodologia de pesquisa bibliográfica, através de materiais já elaborados, como livros, periódicos, artigos, pesquisas em sites de internet. A abordagem das informações coletadas é qualitativa e exploratória, buscando nas fontes consultadas aspectos pertinentes ao tema e que possibilitem encaminhar uma conclusão que responda ao problema proposto.

\section{Gestão Escolar e Inclusão da Criança Down}

\section{Prática pedagógica e educação inclusiva}

O fato de existir uma ampla legislação regulamentadora do direito à educação inclusiva não é suficiente para que esse direito se concretize em situações práticas, pois ao lado da evolução jurídica sobre esse tema devem também evoluir as circunstâncias que permeiam o cotidiano escolar.

Oliveira (2012) enfatiza, quanto a essa questão, que as situações práticas se referem ao contrato pedagógico, ou seja, às relações que professores e alunos estabelecem no cotidiano escolar, as quais permitem que a distância que existe entre o que a legislação estipula e a realidade da sala de aula seja efetivamente superada.

Ainda, Oliveira (2012) observa que nessa questão se incluem intervenções pedagógicas que estabeleçam um contrato a partir do qual as diferenças entre cada aluno, relativamente às formas como estabelecem contato com o seu entorno, possam ser respeitadas, possibilitando a todos, igualmente, o direito a uma educação emancipadora, à vivência de situações que desenvolvam a independência e, paulatinamente, permitam aos alunos adquirirem conhecimentos com autonomia e protagonismo, dentro de suas capacidades.

Complementando, Oliveira argumenta:

Neste ponto, não há mais justaposição e sim síntese dos elementos apresentados, confirmando a conquista da autonomia intelectual. Entretanto, até que o aluno alcance 
esta condição, a mediação docente é necessária. Por isso, importa, para melhorar os processos educativos, entender em que grupo cultural os sujeitos professores se encontram, quais são suas representações sociais e que significado atribuem à educação, pois são eles que vão atribuir significado às práticas escolares e, principalmente, aos conhecimentos dos alunos. (OLIVEIRA, 2012, online).

Em complemento a esse posicionamento, Dotti (2013) se refere às representações sociais presentes nas concepções de professores (especialmente) em relação aos alunos, enfatizando que na escola confluem diversos mundos que compõem um universo maior, no qual circulam ideias, pontos de vista, perspectivas, etc., as quais influenciam as práticas pedagógicas, que as refletem.

Dotti (2013), no mesmo sentido, ressalta que o gestor será promover as condições para que o professor seja capaz de permitir aos alunos serem protagonistas da própria educação e da evolução de seus conhecimentos, sejam quais forem as características que os diferenciam entre si ou as potencialidades que possuam.

Para que isto se torne possível são necessárias adaptações, mas o grupo deve ser sensibilizado para que estas adaptações se incorporem ao cotidiano da escola naturalmente, para que a realidade social da escola inclusiva seja compreendida por todos. Para Dotti (2013), a escola deve proporcionar que também os alunos compreendam e aceitem com naturalidade essas adaptações, enfatizando o respeito mútuo, a convivência e a aceitação da diversidade. Desse modo, conformam-se relações de interdependência que são positivas e que facilitam a realização das tarefas adaptadas para que todos alunos, especialmente os alunos incluídos, participem de todas as atividades de aula de espontaneamente, tenham a liberdade de se relacionar entre si, aprendam conjuntamente e se divirtam coletivamente. Ainda, a prática docente deve buscar intervenções que proporcionem espaço para que os alunos incluídos repitam e imitem os modelos que devem ser assimilados, adaptando-os de forma a se tornarem positivos para a aprendizagem de todos os alunos. (DOTTI, 2013).

Na perspectiva de Roldão, in Rodrigues (2013), a criança Down, quando incluída em uma sala regular, apresenta melhores resultados quando a intervenção pedagógica é flexível, promovendo diversas possibilidades para que ela possa participar da aula, considerando as suas particularidades comunicativas, servindo-se de recursos diversos que atendam às suas necessidades especiais e às suas demandas específicas para aprender junto aos demais colegas.

Complementando, afirma Roldão, in Rodrigues (2013) que a criança Down possivelmente não realizará as atividades propostas no mesmo ritmo das demais crianças, não apresentará o mesmo grau de abstração ou de intensidade, mas o professor deve compreender 
quais os objetivos que devem ser alcançados em termos de aprendizagem e estabelecer, a partir deles, formas de organizar a sua práxis pedagógica através de métodos eficientes para facilitar o processo. Além disso, deve atentar para as formas de avaliação de seu rendimento.

Da mesma forma, Roldão, in Rodrigues (2013) se refere às adaptações curriculares necessárias, as quais se referem a todo o planejamento do processo ensino-aprendizagem e das intervenções do professor. Nesse sentido, devem ser planejados métodos de ensino capazes de contemplar as necessidades específicas dos alunos incluídos como um todo e de cada aluno incluído particularmente. Essas adaptações devem ser orientadas por um professor especializado, permitindo assim que alguns objetivos e/ou conteúdos fixos sejam eliminados ou substituídos e que o processo de avaliação e a terminalidade também sejam alterados.

Ainda, Roldão, in Rodrigues (2013) se refere a algumas das adaptações possíveis, dentre as quais destaca:

a) adaptações na forma como a escola se organiza em termos de grupos de alunos, de conteúdos das grades curriculares, de intervenções didáticas, de espaços, etc.);

b) adaptações de objetivos e conteúdos para priorizar determinadas áreas ou unidades de conteúdos funcionais considerados essenciais, para promover reforços de determinados conteúdos, para estabelecer objetivos precisos, para determinar a sequenciação de conteúdos, etc.;

c) adaptações quanto à temporalidade, em relação aos tempos previstos para que cada atividade seja realizada, a quantidade de horas/aula necessária para que todos os alunos, de acordo com seu próprio ritmo de aprendizagem, possam aprender;

d) adaptações quanto aos procedimentos didático-pedagógicos e às ações próprias do processo de ensino e aprendizagem, promovendo metodologias que sejam acessíveis a todos, modificando a complexidade das exigências das atividades realizadas e utilizando recursos diferenciados e específicos;

e) adaptações nos equipamentos de ensino, enfatizando a realização de atividades prévias à apresentação de conteúdos e de atividades complementares e nas formas de avaliar os alunos para promover conhecimentos qualitativos e desenvolver habilidades adequadas às possibilidades que possuem para aprender;

Sampaio e Sampaio (2010) acrescentam a essas sugestões a ideia dos métodos ativos, que consideram que as atividades que são realizadas na sala de aula são partes de um sistema no qual ocorrem relações entre a prática didático-pedagógica do professor e a estruturação dos conhecimentos dos alunos. 
Os métodos ativos apresentam o diferencial de entender as propriedades que são próprias dos conteúdos didático-pedagógicos. Indo além, se encontram baseadas no aluno. Nesse sentido, de acordo com a forma concreta que as crianças Down têm para aceder ao conhecimento, são propostas situações reais de atividades adaptadas às características dessas crianças e que partem da atividade proposta a todo o grupo de alunos e da forma como cada aluno reage a essa proposição para realizar atividades comuns e coletivas. (SAMPAIO e SAMPAIO, 2010)

A atuação do professor em uma sala de aula na qual existem alunos incluídos deve partir da consideração da necessidade de optar por uma didática inovadora, diferenciada, seguindo os princípios que Beyer (2010) considera relevantes:

1) Práticas didático-pedagógicas que envolvam situações reais, ou seja, que promovam o contato do aluno com a realidade que o circunda, que sejam aplicáveis à vida cotidiana dos alunos e que possuam potencial para que os alunos se comuniquem de forma harmônica e estável, que sejam consistentes e que sejam dirigidas por uma coerência lógica.

2) Em nível psicológico, práticas didático-pedagógicas que consideram a aprendizagem como um processo através do qual cada aluno, de forma pessoal e autônoma, descobre o conhecimento. ou seja, que gradualmente e aos poucos apresente situações concretas para extrair delas juízos mais abstratos, que iniciem em uma abordagem concreta e particular para estender-se a questões mais gerais, que permita que a criança elabore esquemas empíricos e, finalmente; que considerem que a conjectura é um elemento imprescindível.

Para Beyer (2010, p. 27), “disso se obteria alguns princípios possíveis para o desenvolvimento de uma didática especial de ensino que serviria de guia para orientar as adaptações curriculares necessárias", destacando:

a) Os objetivos e os conteúdos de cada nível de ensino devem ser integralmente mantidos.

b) É necessário determinar objetivos que se relacionem com procedimentos e habilidades adequados às capacidades dos alunos.

c) Apresentar situações iniciais que se configurem como situações de ensinoaprendizagem acessíveis e que possam ser manipuladas pelos alunos.

d) Organização das atividades desenvolvidas no cotidiano de classe para atender as capacidades e as possibilidades cognitivas, psicológicas e motoras dos alunos. 
e) Respeitar os ritmos de aprendizagem e de rendimento relativamente ao ritmo de progresso de alunos que apresentam níveis ou idades semelhantes ao aluno incluídos, mas que não sejam portadores de deficiência.

f) Reforçar, em sala de aula, a utilização da linguagem gráfica ou das representações bidimensionais dos conteúdos.

g) Simplificar as informações repassadas aos alunos, evitando, tanto quanto possível, a exigência de que escrevam ou realizem cálculos quando a escola não contar com recursos auxiliares para que os alunos incluídos realizem essas atividades de forma rápida e harmonizada com os demais.

h) Utilizar, em todas as atividades, materiais e recursos pedagógicos que sejam adequados à capacidade dos alunos incluídos.

i) Atuação diferencial do professor.

\title{
A efetividade da inclusão escolar da criança Down
}

Para que se considere que as práticas inclusivas nas escolas regulares são eficientes, sugere Silva (2012, p. 45) que é necessário observar "as atitudes de toda a comunidade escolar em relação aos demais", em relação ao trabalho desenvolvido de forma cooperativa, em relação aos alunos incluídos "[e] em relação à inclusão como processo". O gestor, tendo em vista essa consideração, possui um papel essencial, visto que suas atitudes, seu posicionamento e a forma como orienta o pensamento da escola sobre a educação inclusiva determina a forma como a comunidade escolar pensa, age e reage diante da perspectiva da inclusão.

A autora argumenta:

\begin{abstract}
A atitude se compõe de três dimensões: a) a cognitiva, formada por percepções, crenças e informação que se tem sobre algo; b) a afetiva, que implica sentimentos a favor ou contra algo e; c) a condutal, que se refere à tendência a reagir de determinada maneira diante de alguma coisa. Assim, então, em relação à inclusão, a atitude é um conjunto de percepções, crenças, sentimentos a favor ou contrários e formas de reagir diante da postura educativa que centra seu esforço no alcance da aprendizagem dos alunos. (SILVA, 2012, p. 99)
\end{abstract}

De qualquer forma, a atitude do gestor deve orientar-se por uma premissa fundamental, que é evocada por Dotti (2013, p. 72): “o aluno incluído precisa estar na sala de aula do ensino regular, mas não apenas estar, porque incluir é mudar e transformar o sistema educativo para alcançar a todos". 
Esta ideia é semelhante à perspectiva de Ainscow (2010), que considera que o processo inclusivo deve ocorrer em níveis complementares para que alcance o êxito:

1) O aluno incluído se encontra na escola, embora a sua presença implique na possibilidade de participação.

2) O aluno incluído participa da escola, porque esta the oferece todas as condições de participação na totalidade das atividades propostas, as quais são realizadas por todos.

3) O aluno incluído aprende, adquire conhecimento, porque está presente e participa da escola.

O gestor escolar deve reconhecer, em relação aos professores, que tanto o professor da sala regular como o professor da sala de recursos devem desenvolver atividades baseadas tanto em uma formação prática como em conhecimento especializado na área da educação inclusiva. Desse modo a escola conta com profissionais capacitados para promover, de forma interativa e interdisciplinar, a aprendizagem do aluno incluído.

Como observa Dotti (2013) em relação à sala de recursos, este é um espaço previsto na legislação, que determina a obrigatoriedade de que o aluno incluído esteja presente neste espaço no contraturno escolar. Porém, as atividades que realiza nesses momentos devem ser adequadas às suas necessidades particulares, devem ser significativas para quando estiver presente na sala de aula regular.

No espaço da sala de recursos, portanto, o aluno incluído realiza atividades que favoreçam a ele integrar-se plenamente da sala regular, facilitar seu acesso ao conhecimento e seu progresso acadêmico junto aos demais alunos que se encontram na sala de aula regular de ensino. (DOTTI, 2013)

Ainda, na perspectiva inclusiva, os gestores escolares cumprem papéis essenciais de auxílio à configuração de uma comunidade escolar democrática e verdadeiramente inclusiva.

Tanto em relação aos professores como do orientador e do supervisor educacional, dos demais funcionários da escola e dos próprios alunos, a gestão escolar assume a responsabilidade pela inclusão, considerando-se que cabe ao gestor desenvolver na comunidade escolar a responsabilização de todos pelo êxito do processo.

Nesse sentido, desvenda, analisa, reflete, colabora na crítica do processo, proporciona a formação, a reorganização dos processos internos, as adequações necessárias e se torna a fonte principal e gerenciador da rede de conhecimentos necessários ao êxito da educação inclusiva.

Para Gomes (2013), o gestor escolar deve ser um especialista nas relações dentro da escola, cabendo-lhe buscar elementos da realidade do aluno incluído para discutir e refletir junto 
aos professores, orientação e supervisão, envolvendo os pais para buscar metodologias adequadas aos alunos, demonstrando o quanto é necessário que a escola proporcione aprendizagens sólidas, contextualizadas, fugindo da padronização e promovendo a singularidade dentro do coletivo.

Enfatiza ainda Mantoan (2015) que os conteúdos curriculares devem ser contextualizados à realidade dos alunos e aproximar os conhecimentos de sua vida cotidiana. Essa premissa facilita a obtenção de sucesso e a compreensão dos saberes transmitidos pela escola. O gestor escolar, nessa perspectiva, é aquele que investiga e se aprofunda em todas as situações envolvidas na educação inclusiva, buscando soluções práticas, métodos e técnicas que facilitem a aprendizagem e a democratizem.

O gestor, responsabilizando-se pela coordenação do processo ensino-aprendizagem, assessora a equipe no acompanhamento, na avaliação e na revisão necessária do trabalho. $\mathrm{Na}$ perspectiva da inclusão, seu papel somente é eficaz quando se encarrega de intermediar e de articular o processo inclusivo entre as políticas de inclusão e a instituição. (SILVA FILHO, 2015)

Nesse sentido, conforme Silva Filho (2015), o gestor deve atuar na verificação das dificuldades apresentadas pelos professores e incentivá-los, integrá-los, promover ações formativas que facilitem que o trabalho escolar tenha significado tanto para os professores como para todos os alunos e a comunidade escolar considerada de modo mais amplo. Atento ao cotidiano da escola, deve observar sua realidade, aliando competência teórica, técnica, humana e política, contribuindo para que o processo ensino-aprendizagem se especialize.

De qualquer modo, é fundamental ao gestor escolar compreender que a inclusão requer adaptações físicas (materiais e espaciais), atitudinais (de professores, funcionários da escola e colegas), de recursos técnicos (equipe). Essas adaptações podem ser bastante significativas, mas supõem, sobretudo, uma adequação do currículo aos alunos com Síndrome de Down.

Bautista (2012) enumera algumas dessas adaptações, que devem ser pensadas pelas equipes de orientação e supervisão educacional, juntamente com a equipe gestora da escola, os pais e os especialistas que atuarão junto aos alunos incluídos:

a) introduzir áreas, objetivos e conteúdos específicos que não façam parte do currículo e facilitem a aprendizagem, aprendizagem de habilidades ou estratégias de orientação e de mobilidade, treinamento no manejo de equipamentos especiais, etc.;

b) priorizar objetivos e conteúdos de forma temporal, desenvolvendo as potencialidades de todos os alunos, estimulando a percepção, implementando programas de habilidades sociais 
e competências de relação interpessoal, desenvolvendo a segurança emocional e a independência escolar e social;

c) adaptar a apresentação dos materiais e das tarefas;

d) eliminar objetivos e conteúdos que não ofereçam possibilidades de adaptação ou de modificação;

e) respeitar o ritmo de aprendizagem de cada aluno, visto que a criança Down tem uma aprendizagem mais lenta do que o restante dos alunos e também há ritmos diferentes de aprendizagem;

f) prestar atenção especial à forma de transmissão de conhecimentos, para evitar dificultar a aprendizagem ou a realização de aprendizagens mecânicas ou repetitivas, sem conteúdo experiencial ou um suporte conceitual.

g) modificar o tempo para a execução de cada tarefa, agregando um tempo maior;

h) avaliar sem considerar como critérios as aprendizagens saturadas de componentes cognitivos, realizando adaptações nos formatos de avaliação e nos conteúdos, sempre que possível. Em caso contrário, substituí-los por outros, relacionados com os canais sensoriais de entrada/resposta que o aluno seja capaz de utilizar.

Ainda, mais importante é reforçar que os papéis do gestor escolar, do supervisor, do orientador e dos professores são complementares e codependentes na conformação de uma comunidade escolar inclusiva. O apoio e a cooperação mútuos são determinantes nessa construção, em uma organização escolar que toma suas decisões em conjunto, democraticamente.

É necessário refletir, ainda, que a inclusão de crianças Down (e da inclusão como um todo), contudo, também representa um desafio para o processo ensino-aprendizagem. Diante dessa ideia, especificamente, não deve haver qualquer exceção relativa às classes regulares. Por isso, a reflexão deve ser constante e incentivada em todos os setores que compõem as escolas, direcionada às questões prementes que se referem aos conteúdos, às práticas pedagógicas e ao processo ensino-aprendizagem das crianças Down.

Para Silva Filho e Barbosa (2015, p. 365), de um modo geral, “a distância entre o que é concebido teoricamente e o que é realizado efetivamente, em termos de educação inclusiva, pode ser explicado pelo entendimento que se tem sobre a inclusão". A forma como se percebe a educação inclusiva é um indicativo seguro da necessidade de que se produzam mais informações sobre esse processo, para que sua implementação possa ser realizada com menos incerteza e maior qualidade. 
Carvalho, em referência a essa questão, observa:

\begin{abstract}
Em relação à implementação da proposta da inclusão educacional escolar os gestores encontram: resistências de muitos professores e familiares; dúvidas de outros que se declaram preocupados com o desmonte da educação especial e, também, a aprovação e o entusiasmo de não poucos. A resistência dos professores e de alguns pais é por eles explicada em razão da insegurança no trabalho educacional escolar a ser realizado nas classes regulares, com os alunos com deficiência. (CARVALHO, 2012, p. 27)
\end{abstract}

Carvalho (2012) considera também que os professores manifestam as lacunas em seu processo formativo em relação a alunos portadores de deficiência, tanto em termos teóricos como práticos. Essas lacunas se refletem em resistências e negativas diante da ideia de trabalho com alunos portadores de deficiência em sua sala de aula, havendo professores que aceitam esses alunos porque a direção da escola determina que devam estar na sala de aula e outros que, mesmo sem a formação inicial suficiente, aceitam o desafio de trabalhar com esses alunos e acabam descobrindo que esse trabalho pode alcançar o sucesso.

Em outro estudo, realizado por Gorla (2013) com professor de educação física, as conclusões indicam que a gestão escolar não pode permanecer alheia à necessidade de adotar medidas interdisciplinares que favoreçam a inclusão. Como se percebe, portanto, nenhuma disciplina deve permanecer alheia às adaptações necessárias para que a escola se organize para favorecer o êxito do processo inclusivo.

A abordagem do processo de inclusão de alunos portadores de deficiência, especialmente no âmbito do Ensino Fundamental I, encontra referência ao fato de que os alunos, coletivamente, convivem no espaço escolar, que é rico em diversidade e em diferenças. exigindo-se que a escola reflita sobre a forma como organiza o ensino, sobre a assessoria pedagógica e social necessária, sobre as experiências vividas no processo ensino-aprendizagem, que devem ser significativas e eficientes para todos os alunos, não cabendo qualquer forma de segregação diante dessa postura.

A educação inclusiva na perspectiva da assessoria pedagógica, como observa Gorla (2013), pressupõe uma gestão escolar sempre disposta e aberta a compartilhar com professores e alunos o desafio do processo ensino-aprendizagem inclusivo, embasado no respeito à diversidade como elemento de união de todos e de enriquecimento das experiências vividas no espaço escolar para proporcionar uma aprendizagem também compartilhada, coletiva.

A inclusão de crianças Down na educação regular é atividade relativamente recente no Brasil, mas há diversas controvérsias e discussões a esse respeito, que possibilitam a produção de um vasto material teórico relativo a essa questão. que representa um desafio ainda bastante 
complexo para o sistema educacional. Como se percebe, ainda existem possibilidades de se avançar mais no sentido de uma inclusão efetiva destas crianças, para que encontrem na escola regular um espaço de crescimento e de desenvolvimento, experiências significativas e possibilidades de uma aprendizagem efetiva.

\section{Considerações Finais}

O presente estudo discorreu sobre o tema da assessoria pedagógica para o atendimento de crianças Down e cumpriu com o objetivo de determinar as formas de intervenção da gestão escolar para tornar efetiva a inclusão de crianças Down em classes regulares de ensino, sua aprendizagem e desenvolvimento.

Para tanto, discorreu sobre a prática pedagógica e a educação inclusiva e apresentou elementos necessários à efetividade da inclusão escolar em geral e da criança Down, especificamente.

Inicialmente, é possível chegar à conclusão de que o processo de inclusão do aluno portador de deficiência nas escolas regulares alcançará a eficiência esperada, seguindo a legislação existente, quando a gestão escolar integra e assume com protagonismo, a realização das alterações e adaptações que possam permitir que essa eficiência se concretize.

Assim sendo, considerando-se que a perspectiva da educação inclusiva ainda pode ser considerada como algo recente e em evolução, várias ações e atitudes são necessárias para que a gestão escolar proporcione que se estabeleça na escola uma visão inovadora, que se desenvolva uma cultura de aceitação, acolhida e respeito à diversidade dos alunos, proporcionada por uma assessoria pedagógica que responda às necessidades, às diferenças, aos ritmos e às maneiras pelas quais cada aluno aprende.

Ainda, conclui-se que no âmbito de uma gestão escolar democrática, o processo da educação inclusiva no Ensino Fundamental I se torna uma dinâmica de cooperação e de organização que sempre é perpassada pelo respeito às diferenças e de abertura às necessidades do outro, sendo um processo de negociação aberto e dinâmico, pelo qual cada membro da comunidade escolar se sente responsável e participante.

Da mesma forma, para promover a educação inclusiva a gestão escolar deve se organizar privilegiando a união harmoniosa da qualidade do atendimento educacional especializado e da qualidade do exercício profissional do professor em sala de aula. Ao agir dessa forma, o gestor permite que a comunidade escolar, considerada em sua totalidade, vivencie a experiência de 
uma verdadeira comunidade educacional, na qual exista a aceitação, a solidariedade, a diversidade, o respeito, a compreensão e os direitos humanos.

Essa comunidade deve também compreender que o convívio social da criança Down com outras crianças pode oferecer a efetivação de relações de respeito, dignidade, a construção da identidade, da cidadania e a organização de regras sociais de forma justa, respeitosa e solidária.

Nesse sentido, contempla o pressuposto da educação como o desenvolvimento de cada ser humano em suas diferentes potencialidades, sem enquadrá-las a critérios determinados. No âmbito do Ensino Fundamental I, proporciona que cada aluno possa vir a se autoconhecer, aprender a conviver e desenvolver suas próprias reflexões sobre seu comportamento, formandose como cidadão, de forma equilibrada, para a tolerância e a convivência em uma sociedade plural e, talvez, mais justa e humana.

Da mesma forma, também se conclui que a magnitude do benefício da inclusão, da heterogeneidade desde as séries iniciais, se torna um grande aliado para toda a escola na luta contra a discriminação, o estigma e o preconceito. Quando o processo de inclusão é conduzido pelo gestor dentro dos parâmetros sugeridos no presente estudo, os alunos descobrem serem capazes de atos solidários e cooperativos, tornando-se mais compreensivos, tolerantes e confiantes nas relações com os outros.

Esse valor se reforça quando se considera que os discursos oficiais e a inserção dessa temática nas discussões e nos estudos que atualmente têm sido desenvolvidos sobre a inclusão de crianças Down evidenciam não somente uma preocupação crescente com a melhoria contínua em termos de formação de profissionais e de especialização de recursos, mas, sobretudo, o reconhecimento, por parte da comunidade escolar, das múltiplas dimensões e possibilidades da educação inclusiva, materializando-se em avanços importantes quanto ao êxito da inclusão.

Nesta perspectiva, avalia-se que a gestão escolar, na realidade dos currículos, dos conteúdos e das práticas pedagógicas da educação inclusiva, apesar do processo inclusivo estar ainda em vias de implantação e aperfeiçoamento, pode e deve lançar um novo olhar sobre as possibilidades da educação inclusiva e, especialmente, sobre as crianças Down que ingressam na escola. 


\section{Referências}

AINSCOW, Mel. Desarrolo de escuelas inclusivas: ideas, propuestas y experiencias para mejorar las instituciones escolares. 2 ed. Madrid: Narcea, 2010.

BAUTISTA, Rafael. Necessidades educativas especiais. 2 ed. Lisboa: Dinalivro, 2012.

BEYER, Hugo Otto. Inclusão e avaliação na escola: de alunos com necessidades educacionais especiais. 3 ed. Porto Alegre: Mediação, 2010.

CARVALHO, RositaEdler. Educação inclusiva com os pingos nos is. Porto Alegre: Mediação, 2012.

DOTTI, Corina Michelon. Diversidade e inclusão: reconfiguração da prática pedagógica. 12 ed. Caxias do Sul: Educs, 2013.

GOMES, Márcio. Construindo trilhas para a inclusão. 2 ed. Petrópolis: Vozes, 2013.

GORLA, José Irineu. Educação Física Adaptada. São Paulo: Phorte, 2013.

MANTOAN, Maria Teresa Édler. Inclusão Escolar: o que é? Por quê? Como fazer? São Paulo: Summus, 2015

OLIVEIRA, Carolina da Cruz Jorge de. Ciclo de discussões sobre as concepções de aprendizagem: internalizando novos saberes. In: Seminário de Pesquisa em Educação da Região Sul, 09, 2012. Disponível em

http://www.portalanpedsul.com.br/admin/uploads/2012/Formacao_de_Professores/Trabalho/02_26_39 _249-6896-1-PB.pdf>. Acesso em 1º de agosto de 2017.

ROLDÃO, Maria do Céu. Diferenciação curricular e inclusão. In RODRIGUES, David (org.) Perspectivas sobre a Inclusão: da educação à sociedade. 2 ed. Porto: Porto Editora, 2013, p. 85-99.

SAMPAIO, Cristiane T., SAMPAIO, Sônia Maria R. Educação inclusiva: o professor mediando para a vida. Salvador: EDUFBA, 2010.

SILVA FILHO, Raimundo Barbosa da; BARBOSA, Elma do Socorro Coutinho. Educação Especial: da prática pedagógica à perspectiva da inclusão. Educação Por Escrito, Porto Alegre, v. 6, n. 2, p. 353368, jul./dez. 2015.

SILVA, Maria Odete Emydio da. A análise de necessidades na formação contínua de professor: um contributo para a integração e inclusão dos alunos com necessidades educativas especiais no ensino regular. 2 ed. São Paulo: AVERCAMP, 2012.

\section{Como citar este artigo (Formato ABNT):}

DANTAS, Denise Rodrigues; ACOSTA, Juan PabloWeschollek. Gestão Escolar: Assessoria Pedagógica para o Atendimento de Crianças Down. Id on Line Rev.Mult. Psic., 2018, vol.12, n.42, Supl. 1, p. 674-687. ISSN: 1981-1179.

Recebido: $14 / 11 / 2018$

Aceito: $16 / 11 / 2018$ 